\title{
Empirical Analysis of Factors Affecting University Graduate Employment and Route Optimization Study
}

\author{
Chonghong WEI \\ Shandong Women University, Jinan Shandong, 250002, China
}

\begin{abstract}
Based on current situation of undergraduate employment difficulty in recent years, this paper makes a comprehensive analysis of reasons resulting in university graduate employment difficulty through reviewing and summarizing research results of different scholars at home and abroad, including social, university and individual aspects and relevant employment theory. Aiming at the basic employment status of university graduates at home and abroad, it also puts forward thoughts and suggestions from the perspective of government, society, university and individual and makes a brief comment on current researches.
\end{abstract}

KEYWORD: University graduate; employment; influencing factor; research overview

\section{INTRODUCTION}

Popularization of higher education in China has given rise to increasing number of university graduates, making employment pressure increasingly larger. Hence the employment rate of university graduates has become one of the concerns of the society. Whatever the graduate or the parent expects a suited job, which requires joint efforts of government, university and graduate together to open a door of successful employment. Therefore, it is especially important to find out current employment status and systemize relevant influences for undergraduate employment difficulty.

\section{BASIC EMPLOYMENT INFORMATION AT HOME AND ABROAD}

The current employment situation of university graduates in China is not optimistic. There are over millions undergraduates can not find a job. With constant growing of Chinese population, the higher education has entered into the stage of popularization and the number of university graduates is increasing gradually. By the year of 2014, the number of university graduates has reached 7.27 million, which has increased by 280 thousand compared with 2013. It also means undergraduates of 2014 have a larger employment pressure.

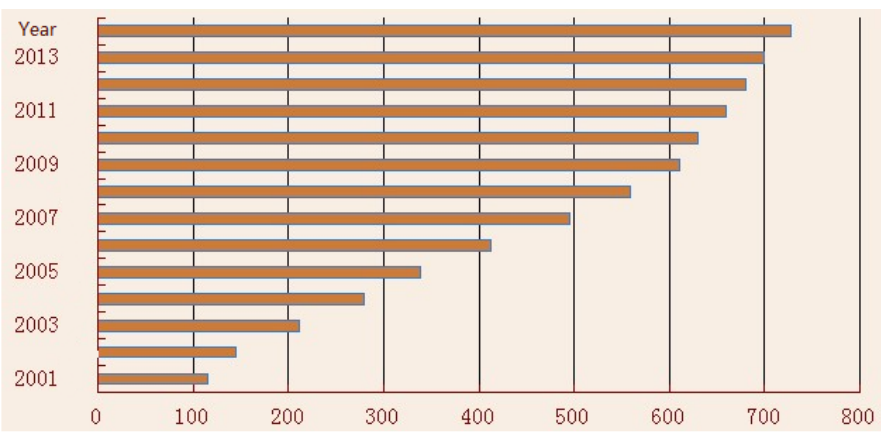

Figure 1 The number of college graduates (2001-2014). Source: China education online

By reviewing the data, we can get the employment rat e of undergraduates from 2010 to 2013: the overall employment rate of undergraduates of 2010 is $89.6 \%$ after they graduated for half a year, and the average monthly income was 2479 Yuan after half a year. The employment rate had surpassed the level before international financial crisis. The employment and monthly income had been increasing constantly by $3 \%$ and $4.1 \%$ respectively compared with the undergraduates of 2009 and 2008; the employment rate of undergraduates of 2011 was $90.2 \%$ after they graduated for half a year, a little higher than last year. The employment rate of higher vocational college is $89.6 \%, 1.5$ percent higher than that of last year. $50 \%$ of the undergraduates were satisfied with their employment; the employment rate of undergraduates of 2012 was $91.5 \%$, a little higher than 2011 (90.8\%). The overall contracting process of university graduates of 2013 was apparently slower than that of the last year. The signing rate of master 
graduates of 2013 was $26 \%, 11$ percent lower than that of the same period in 2012; the signing rate of undergraduates was $35 \%, 12$ percent higher than that of the same period in 2012; the signing rate of higher vocational college graduates was $32 \%, 13$ percent lower than that of the same period in 2012. As for the employment rate after they graduated for half a year, it was $90.9 \%$ for the undergraduates of 2012 , higher than the employment rate of $90.2 \%$ for the undergraduates of 2011. [Mycos, Report on Chinese University Graduate Employment (2011-2013)]

Comparatively speaking, the education level of western developed countries is at the forefront of the world, whereby the United States is one with faster development of higher education. Without doubt, current employment difficulty of university graduates is also the main problem faced with them. According to the report, the unemployment rate of America has risen to $6.1 \%$. At the same time, according to "Employment Outlook Survey" issued by Milwaukee Human Resource Company, America has the poorest prospects of the current employment for the recent 12 years, and that more than half of the university students become the unemployed after graduation.

Japan is also the economy and education power in the world. The survey results issued by Ministry of Education, Culture, Sports, Science and Technology (MEXT) in August 7, 2013 showed that the employment rate of Japanese undergraduates graduated in this spring had reached $67.3 \%, 3.4 \%$ higher than that of the last year. The data had increased for continuously three years. According to MEXT, this is the result of economy resumption, however it must be improved that twenty percent of undergraduates haven't got a stable employment. From the survey, there were 116 thousand persons without a stable job including temporary workers such as part-time workers, wage earners as well as the graduates that neither entered a higher school nor obtained employment.

Relatively speaking, as the total population of Germany in central Europe is declining gradually, the labor will higher education is in short. Therefore, the overall situation of university graduates is favorable. The unemployment rate of German university graduates in 2011 was only $2.4 \%$, almost achieving full employment.

\section{RELEVANT EMPLOYMENT THEORIES}

The employment theory is becoming more and more modernized with continuous development of the time. Western employment theory comes into shape under the over-all situation of capitalist market economy.

\subsection{Classical Employment Theory}

The classical employment theory was put forward by classical economists represented by Say. According to the theory, labor is regarded as an important part of market economy. The employment in labor market can be completely adjusted by the market to realize full employment.

\subsection{Keynesianism}

Keynesianism is generated after the serious economic crisis and career occurred in the capitalism world. The main viewpoint is to intervene with economic development by playing the role of national government for the purpose of boosting domestic demand and relieving employment. Although Keynes realized the disadvantage of market regulation, he still regarded labor as the means of production and condition under market economy.

\subsection{Domestic Employment Theory}

The employment theory concerning Chinese employment was gradually built up after the reform and opening-up policy. The employment theory of Marxism was carried out according to national condition of China and became Chinese-style employment theory mainly from the perspective of labor market, which puts emphasis on institutional influence on employment, and the perspective of demography, that is, health, education, sex, labor participation rate of the labor, as well as the perspective of labor property.

\section{RESEARCH SIGNIFICANCE}

University graduates are main forces of labor market as well as state pillars in the future. They shoulder the glorious mission of revitalizing the Chinese nation and carrying forward Chinese culture. Only by distributing human resources correctly and reasonably, can the strategy of reinvigorating China through human resource development be better carried out. It is concerned with whether the highereducation talents can fully play a role and serve the society on their own knowledge learned, as well as technological development, economic development, cultural development and rich country and strong people of the nation.

With respect to university graduate employment, it has made a certain influence on university graduates from job distribution in the past to twoway selection between the graduate and the unit in the present, and from elite education to "popularization" through enrollment expansion of colleges and universities. With increasing number of graduates, the employment pressure has become 
more and more large. If it can not be solved in time, it will certainly bring about great social concerns. From existing researches, many scholars have analysed and researched university graduate employment detailedly and variously. However, it needs to be further deepened as for some aspects.

At present, employment difficulty of university students has given rise to a wide concern of the society. When it comes to the senior year in July every year, it will attract the attention of various parties, all of whom expect a better employment rate. The employment rate concerns every aspect of the society such as reform and development of higher education, talent introduction of the unit and social stability promotion, etc. Therefore, study on the factors affecting employment difficulty of university graduates is of great significance for selfvalue realization of university students, as well as return of educational investment for the parents, healthy development of higher education and social harmony promotion.

\section{EMPIRICAL ANALYSIS OF FACTORS AFFECTING EMPLOYMENT}

There are a great many factors affecting university graduate employment. According to investigation and analysis of previous scholars as well as relevant pertinent document literatures, the factors have the characteristics of the following aspects:

\subsection{Social factor}

During the process of Chinese university graduate employment from "job distribution" to "two-way selection, self-service employment", all orders of society have made a great contribution. However, there still exist institutional obstacles in university graduate employment. As Luo Sangui (2006) pointed out, China was lacking in market supervision of university graduate employment, that the competitive mechanism of employment was not fair enough, and that imperfect flow mechanism for talents had caused university graduates unable to find a suited post among various resources. $\mathrm{Yu}$ Hongyu (2012) indicated that the oversupply contradiction in the labor market was quite sharp, mainly caused by overlap between new labors and unemployed labors. In addition, current employment market for university graduates had been influenced more or less by sex, education background, age and family register. Jin Xizai and Zhu Zhiqiang (2005) considered regional disparity as another factor affecting university graduate employment. Undergraduates were in great demand in the eastern coastal areas, economic developed area and some center cities. As more and more students have limited the employment in large cities such as
Beijing, Shanghai and Guangzhou, the demand and supply in central and western regions have been falling constantly.

\subsection{University factor}

Zhang Yi, Lv Zhenhua, Luo Yongjun, Zhang Wei (2010) pointed that although the nation continued to increase investment in higher education and the university was constantly expanding enrollment scale and adding a number of majors, some university did not set the major from the perspective of market demand, leading to serious demand-supply unbalance and little favorable position for the students to make use of their skills after graduation. $\mathrm{Yu}$ Hongyu (2012) showed that since college expansion plan in 1999, the number of universities and new student enrollment had been increasing, however insufficient national investment in higher education had given rise to declining operating condition, which had brought down education quality by a great extent.

\subsection{Personal factor}

Chen Zhe (2004) held that there was still gap between university graduates and employer requirement. As China entered WTO, the employer had put forward higher requirements for knowledge structure and foreign language level of talents. They thought undergraduates had a poor operational and practical ability and innovation ability. Peng $\mathrm{Yu}, \mathrm{Du}$ Liyan (2010) came to the conclusion that some university students were lack of understanding and cognition of themselves and occupations. They could not have a correct location for themselves. At the same time, they were lack of awareness and understanding of current employment situation. In addition, university graduates were not psychologically prepared during the employment and could not adjust their mentality to face setbacks and difficulties encountered during employment positively.

\section{RESEARCH OVERVIEW AND PROSPECT}

The employment difficulty of university graduates has raised a wide concern of all sectors of society, and the factors have been researched and analyzed by various scholars. It is extremely urgent to solve the problem of employment difficulty of university graduates. No matter government, university, employer and undergraduate, they need constant adjustment and negotiation between each other to eventually gain the proper solution.

With respect to social factor, it required government to strengthen the institutions and policies concerning the employment, establish and 
improve market mechanism for employment, build employer employment market for supervision and arbitration, intensify public functions of the government so as to become the true defender for interests of the masses, and as well deepen policy reform in order to promote successful employment of university graduates.

With respect to the university, it shall train operational ability and innovation ability of students, teach them to learn knowledge at the class and put the learned knowledge into practice and as well enhance student quality in various aspects. In the class, the teacher shall introduce the latest knowledge and skill to help students to improve their employment abilities so as to bring along their dynamic extent. On the basis of using advanced educational theory of western developed countries for reference and by combination of current situation of China's education, we have formed an education mode of our own in order to better cultivate a number of talents for the nation and for the society.

With respect to the graduates, they shall establish correct employment concept, have the positive attitude, get to know more about relevant employment policies and learn more knowledge to lay foundation for the employment. University students shall get more practice during daily learning and living, such as taking part in some extracurricular activities to become open and careful and generous, training themselves into the talent required by the society and the employee.
I believe that under the support of effort of various aspects, the university graduate employment will be increased rapidly and more and more university graduates will find the suited post. The nation and the employee will gain the required talents to joint efforts to build our beautiful motherland.

\section{REFERENCES}

[1] General Office of the State Council, Guo Ban No. [2002]19, Mar. 2, 2002.

[2] Peng Yu, Du Liyan, Cause and Countermeasure for Psychological Problems of University Graduate Employment, Heilongjiang Researches on Higher Education, 2010(01)

[3] Jin Xizai, Zhu Zhiqiang, Current Situation, Problem and Countermeasures of Chinese Undergraduate Employment, Economic Review, 2005(02).

[4] Zhang Yi, Lv Zhenhua, Luo Yongjun, Zhang Wei, Status Analysis and Countermeasure Discussion of Undergraduate Employment under Current Economic Situation, School Party Construction and Ideological Education, 2010(04).

[5] Yu Hongyu, Status Analysis of Undergraduate Employment, 2012(23).

[6] Luo Sangui, Study on Obstructive Factor and Countermeasures of Marketization of Undergraduate Employment, Modern University Education, 2006, (4): 102-106.

[7] Chen Zhe, Analysis of University Undergraduate Employment Difficulty and Occupation Location at Present Stage, the Society, 2004(8): 37-39. 